\title{
The Impact Of Different Uses Of Information Technology On Business Processes And Performance: An Active Learning Exercise
}

Vidya N. Awasthi, (Email: vawasthi@seattleu.edu), Seattle University Sarah Bee, (Email: bees@seattleu.edu), Seattle University

Kevin Kobelsky, (Email: kevin_kobelsky@baylor.edu), Baylor University

\begin{abstract}
Information technology (IT) spending now accounts for $23 \%$ of private non-resident investment, totaling $\$ 305$ billion and nearly equaling the investments in structures and outstripping all other categories. Notwithstanding IT's importance the study of how different uses of IT have varying impacts on organizational processes and performance is the focus of few teaching materials. Since most students lack work experience, having students fully appreciate the nature and performance impacts of different uses of IT is challenging. To address this, we propose using the Aero-BAK Inc. simulation as a single class period active learning exercise. In the simulation students experience how the impacts of technologies that enhance communication and analysis capabilities (a surrogate for investment in informating IT) are different from those that perform physical tasks via a "robot" (a surrogate for automating IT). This helps students make more informed IT capital budgeting decisions. The exercise can be used in an introductory AIS, MIS, or operations management course, and with any textbook.
\end{abstract}

\section{LEARNING OBJECTIVES}

\section{I.1. Introduction}

The primary learning objective of the Aero-BAK Inc. classroom simulation is to help students understand the difference between IT's use to automate business processes versus its use to "informate" them and how this difference affects business performance (Zuboff, 1988). Enabling students to understand this using an active learning exercise is beneficial for two reasons. First, the topic is an important one for managers. Returns obtained from IT investments by businesses are high enough on average to warrant the significant investments made, but they also vary enormously. This is in part because different ways of using IT have different impacts on business processes and performance. This is true for IT in general, and is especially germane to ERP systems (see Theoretical Background below). Second, most students lack meaningful work experience in business operations settings, limiting their ability to appreciate the nature and impact of these differences in IT use. The experiential nature of a simulation helps to overcome this. We are not aware of any other simulations that address this topic.

The simulation provides a springboard for engaged, meaningful classroom discussion. Students are more committed to learning and learn more when instructors use active learning techniques (Becker, 1998). Previous research suggests that no single teaching technique can address the variety of learning styles that students bring to class (Tallmadge et al., 1969). Using a variety of learning strategies leads to greater success in student thinking and learning (Meyers and Jones, 1993, p. 17). Simulations expand and reinforce basic intellectual, communication and interpersonal skills of students. According to Brookfield (1990, p. 115): 
Participating in simulations and role plays involves students in crossing psychomotor, affective, and cognitive domains and calls upon them to be alert to a wide range of stimuli. Because of the emotional tone of such exercises, they often engage students much more directly and vividly than do more reflective activities such as reading or listening. Because this kind of learning involves the whole person-intellect, feeling, and bodily senses-it tends to be experienced more deeply and remembered longer.

It has two types of teams (Automate and Informate) use Lego Toys blocks to manufacture airplanes for a single 75 minute class period (Figure 1). It takes approximately 50 minutes to execute, including 15 minutes to set up, 5 minutes per round for four rounds ( 20 minutes), and five minutes between each round (15 minutes). This leaves the remainder of class time ( 25 minutes or more) for discussion and review of key learning objectives. The simulation is described in detail in the student handout (Section II).

The design of the simulation is such that it allows students to compare the effects of IT that automates, i.e., replaces less physically efficient human labor or equipment with new technology, to the effects of IT that "informates" i.e. enhances workers' and managers' ability to communicate and analyze information. The "robot" added to the Automate team in round three (as explained in Section II) gives them more direct productive resources than the Informate teams, providing a baseline to assess the performance impact of investments in IT that automate. The higher level of communication, discussion and analysis possible in the Informate teams proxies for the capabilities created by using IT to informate. Documented feedback from students who have participated in the simulation demonstrates that it provides insight that they can apply directly in understanding IT investments.

The simulation is not an empirical research study and accordingly is not a controlled experiment designed to determine if one use of IT yields higher performance than the other. It is a pedagogical tool to help students understand differences in the nature and effects of two different uses of IT that have already been established in extensive theoretical and empirical research and are particularly applicable to ERP systems. The simulation does not employ software or robots, removing the technological barriers associated with computer-based simulations. Use of this simulation addresses Albrecht and Sack's (2000) recommendation that an accounting curriculum should examine "technology in business and decision making (technology as a business aid and the impact of technology on business strategy)."

The simulation can be used in any introductory Accounting IS, MIS, or production/ operations management course, and can be used with any textbook. The authors have used the simulation in undergraduate and graduate Accounting IS courses as an introduction to the value of ERP systems.

\section{I.2. Theoretical Background}

The past forty years have witnessed a rapid rise in the use of information technology (IT) to enhance manufacturing performance. US corporate investment in computer hardware and software has grown from 5\% of non-residential fixed investment in 1977 to $23 \%$ in 2005, totaling \$305 billion, nearly equaling investments in structures and outstripping all other categories (Bureau of Economic Analysis, 2006). Econometric research investigating IT's relationship to performance and the so-called 'productivity paradox' has been conducted in the past decade at the firm level (Brynjolfsson and Hitt, 1995; 1996) and industry level (Stiroh, 2001). This research confirmed the story lines dominating the business press: returns are high enough on average to warrant the significant investments made, but they also vary enormously (Brynjolfsson, 1994; Brynjolfsson and Hitt, 1995; 1996). Some firms have exploited IT to generate spectacular operational and strategic benefits (Kraemer et al., 1998) while others have experienced equally spectacular failures (Financial Times, 1998). Chief executives are often disappointed with the ability to wring value out of IT investments (Compass, 1999). As Brynjolfsson (1994) points out:

Perhaps the most important reality is that despite what the statistics say about the 'average' return on IT investment, each manager must decide which projects are worthwhile. There is no bank where companies can deposit IT investments and withdraw an "average" return...Productivity does not automatically follow IT dollars... 
The risk of disappointing returns on IT investments makes proper selection of IT a critical issue for general managers and controllers. Some assert that how a firm invests in IT is more important than how much it invests and that senior managers must understand how IT will affect critical business processes in order to create value (Forrester, 2002; Ross and Weill, 2002; Wessel, 2002). Companies who manage their IT investment most effectively generate returns as much as $40 \%$ higher than those of their competitors (Forrester, 2002).

The primary learning objective of this simulation is to demonstrate that different uses of IT have different effects on business processes and performance. Extensive theoretical (Zuboff, 1988; Gurbaxani and Whang, 1991; Schein, 1992; Venkatraman, 1994) and empirical research (Flynn and Flynn, 1999; Dehning and Richardson, 2002; Dehning et al, 2003; Oh, Kim and Richardson, 2006; Ranganathan and Brown, 2006) in information systems and accounting information systems indicates that IT creates business value in two ways: (A) by improving the efficiency and/or quality of some physical aspect of a process through automation (e.g., robotics and high volume transaction processing systems) and (B) by enhancing information sharing and communication which in turn facilitates improved understanding and action by users in that process and enhanced integration across processes (e.g., local and wide-area networks and data mining software). Hereafter we use the term 'informate', as coined by Zuboff (1988), to describe this use of IT. ${ }^{1}$

Though the two uses of IT are distinct they are not mutually exclusive. Automation, in addition to its primary physical impacts, facilitates information sharing to the extent it captures data relating to the process it is performing. "Devices that automate... also register data about those automated activities, thus generating new streams of information" (Zuboff, 1988 p.9). But however information is gathered, it may or may not be shared or analyzed. Barriers to sharing are both technological and organizational. Using IT to informate facilitates the organization and sharing of information across business processes to create value. This includes not just telephone systems and email, but also the databases and application interfaces that facilitate information sharing and analysis in an organization.

In the context of an ERP system, automate type applications such as billing, payroll, check clearing and customer reservation systems improve the efficiency of business processes. Informate type applications such as process control, sales analysis, and inventory management systems process information for further analysis by process managers and sharing with other business processes. The two uses of IT are not mutually exclusive, and may coexist in the same system or even the same application. "Automate...[type systems] often include... informate type features. Examples include: Aged debtor analysis produced by billing systems and stock re-order information produced by inventory control systems" (Algeo, 1999). Thus an ERP system implements both uses of IT to improve organizational effectiveness (Ranganathan and Brown, 2006). This does not imply that the two uses of IT are indistinguishable. In their study of market reactions to ERP investment announcements, Ranganathan and Brown (2006) find evidence of higher returns accruing to firms with ERP systems having greater functional or physical scope. They conclude that the performance impacts of IT's use to informate are significant and distinct from those associated with transaction processing.

\section{I.3. Business Practice Background}

The following two cases illustrate how these two different uses of IT have different impacts on business processes and performance. DaimlerChrysler upgraded its Toledo Ohio automobile assembly plant, which has been building Jeeps since 1941, in 2001. The plant uses IT in both ways to support communication with suppliers and robotics and have realized substantial productivity benefits. Requirements are 'broadcast' to suppliers three hours before the parts are needed, and parts customized for specific automobile VINs (vehicle identification numbers) are shipped to provide sequenced parts delivery. In the new plant, an engine cradle is "conveyored under a Jeep body, where it is lifted up and bolted in to place by robots, one every 64.28 seconds" (Seikman, 2002). Highly complex

\footnotetext{
${ }^{1}$ While some frameworks use different labels (e.g. Venkatraman (1994) uses 'localized exploitation' and 'internal integration' rather than informating use of IT, and Ranganathan and Brown (2006) use 'transaction processing' and 'organizational integration') and others further decompose informating IT into subcategories (e.g. Schein, 1992; Dehning and Richardson, 2002; Dehning et al, 2003; and Oh, Kim and Richardson, 2006 use informate and transform), the distinction between automation and informate ITs is central to all these studies.
} 
robots are also used to install windshields and rear axles. These coordination and automation IT changes, together with other factors, enabled the production and control worker time required to produce a Liberty Jeep to decline from 26.11 to 22.54 hours. (Seikman, 2002).

The Romeo Engine Plant also uses IT to improve communication and integration with outstanding results. A Machine Monitoring System (MMS) signals when a defective piece has been made or a machine has stopped. In addition, a paging system notifies skilled maintenance workers if repairs are needed. The paging system also facilitates authorization for purchases or maintenance by team managers. The performance benefits stemming from improvements in communication are described well by an hourly maintenance coordinator:

In a regular plant I would be running all over the floor just trying to gather the information that the MMS and Paging systems provide. With this information already provided and with the improved communications, I have more time to devote to quality planning, productivity group meetings, and team meetings. Instead of running around the plant floor putting out fires, I now have time for preventive, long-term strategic planning to solve our maintenance problems. (Kaplan and Hutton, 1997)

In addition to a machine monitoring type system, ERP can take informate capabilities one step further. "For example, a quality alert captured at the automation layer, is pushed into the supervisor's dashboard or portal, where the appropriate action can be triggered. At the end of a shift, this information can be aggregated, and reports created to give the business an overview of performance. By attaching this data to the cost information in ERP, businesses can pinpoint the products, shifts, equipment, operation-even plants-that are profitable or losing money." (Bhattacharya, 2005). Thus, by integrating subsystems such as manufacturing with vendor and customer information, ERP systems enhance information sharing and analysis leading to reduced cycle time for quotations (Jenson and Johnson, 1999), lower inventory levels, and increased on-time product delivery (Bingi, Sharma, and Godla, 1999).

\section{I.4. Implementation Guidelines}

The simulation can be run in virtually any physical classroom layout: flat or tiered, with fixed or movable desks. It requires sufficient Lego blocks be purchased to assemble planes through four or more rounds of the simulation. The blocks required are listed in Table $1 .{ }^{2}$ Production is estimated to be $15-40$ planes per team, per round. Thus, in a class of 25-35 students, four teams playing for four rounds will require blocks for 450-550 planes. Assuming a cost of approximately $\$ 1.50$ per plane, there will be a one-time cost of $\$ 675-\$ 825$ for the materials. For every additional 5-8 students in the class, another group will be formed, requiring proportionately more blocks.

As the simulation approaches, the blocks needed by each team for all four rounds (i.e. for 130 planes per group) should be put into a separate plastic tub or bag for distribution at the beginning of the simulation.

\section{I.5. Evidence Of Efficacy}

Two factors enhance the efficacy of this simulation: first, it can be carried out in one 75 minute class period, and second, it does not require installation or use of any computer software or hardware. These factors significantly reduce the preparation required by the instructor, and eliminate distractions introduced by software or hardware difficulties.

Student feedback from five runs of the simulation indicates that this approach engages and motivates them more effectively than traditional techniques by stimulating them physically, intellectually, and socially for a class meeting in a way that they enjoy. In response to the question, "What did you like the most about it?" a student responded:

\footnotetext{
${ }^{2}$ The plane pictured in Figure 1 is a suggested product configuration. Lego blocks can be purchased as LEGO Bulk bricks at http://www.lego.com The cost per plane is approximately $\$ 1.50$. Alternatively, the instructor may design his or her own product based on their Lego inventory. The original simulation was performed with cars. We suggest building airplanes here because car wheels are not readily available from Lego.
} 
I liked the hands-on aspect of the simulation. If our guest speaker had just come in and said that adding communication IT can be more beneficial than automation IT, I might not have believed it. However, doing the simulation allowed me to see his claims first hand. Also, it was fun to work with my classmates.

In response to "What were the significant things you learned in the exercise?" a student responded:

The important insights I gained from the simulation related to the roles IT has in an organization. Coordination can be more valuable than automation because only some companies can see an immediate improvement in their production process. These companies must remain in synch with other departments for automation to be effectively productive. Automation has certain capacities and reaches a plateau in which improvements level out. However, IT will continually improve business because it makes possible the sharing of information with other departments, suppliers, and vendors.

Representative comments from several other students are listed in Appendix A. Instructors who have delivered the simulation (all of the authors) have found that students experiencing it remember and apply the principles learned to material covered in subsequent classes. Taken together, these comments and experiences provide significant evidence that students are able to related the simulation to the differential performance impacts of the two uses of information technology, the pedagogical goal of the simulation.

Faculty colleagues who have either participated in or heard feedback from students about the simulation are very interested and supportive since there are relatively few simulations in Accounting IS and MIS courses and none on this specific topic.

A limitation of the simulation and debriefing is that it while it may identify several social factors limiting communication, it does not formally examine the social and technical factors that moderate the relationship between IT investment and IT's impact on processes. One approach to explore this and build on the students' experience in the simulation would be to discuss these factors in a subsequent class. 


\section{THE AERO-BAK SIMULATION}

In this simulation, you will work as a member of a team competing against others to manufacture airplanes for Aero-BAK Inc. using Lego Toys blocks. A picture of the airplane prototype is provided in Figure 1 and the Bill of Materials is given in Table 1. The simulation will take approximately 50 minutes to run, including 15 minutes of setup, 20 or more minutes of actual manufacturing (broken up into 4 or more 5 minute rounds), and 15 minutes of breaks between rounds to count inventory and calculate profit. The goal of each team is to maximize its profit over the four or more 5-minute rounds. After the simulation your instructor will lead a discussion of the factors that increase performance. May the best team win!

FIGURE 1

Airplane To Be Assembled

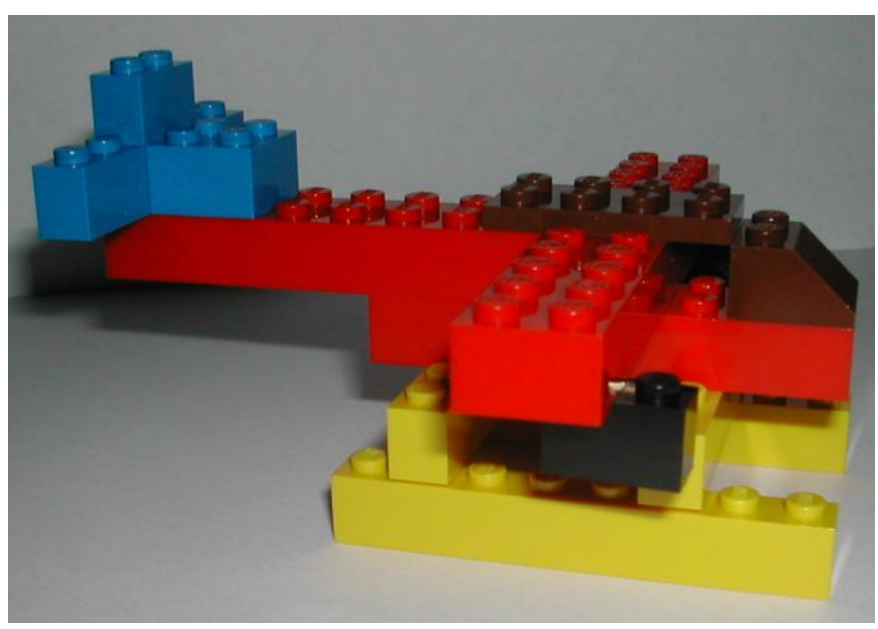

Table 1

Bill Of Materials (Lego Toys Blocks)

\begin{tabular}{|c|l|}
\hline \multicolumn{2}{|c|}{ Bill of Materials Airplane } \\
\hline 1 & $1 * 6$ blue (rudder) \\
\hline 2 & $1 * 6$ yellow (skid) \\
\hline 2 & $1 * 8$ yellow (skid) \\
\hline 2 & $2 * 8$ red (fuselage) \\
\hline 1 & $2 * 2$ blue (rudder) \\
\hline 2 & $1 * 2$ black (engines) \\
\hline 1 & $1 * 2$ blue (rudder) \\
\hline 1 & Flat $2 * 4$ black (fuselage) \\
\hline 1 & $2 * 2$ bottom black roof tile (cockpit) \\
\hline
\end{tabular}




\section{II.1. Types Of Teams}

The manufacturing is done by two types of teams: Automate and Informate. ${ }^{3}$ The class will have one or two Automate teams and two or more Informate teams, each starting with an equal number of members ${ }^{4}$. Most of you will be assigned to a team and then one of the teams will volunteer (or will be selected randomly) to become the Automate team. The remaining teams will work as Informate teams. The way each team will operate is described below.

Once your team's members and type have been selected, each must select an Accountant to count inventory and calculate profit at the end of each round (see description below). The Automate team(s) must also select a Supervisor. Students who are not allocated to an assembly team in order to keep team sizes equal act as Consultants (see description below). One or more Consultants will switch roles to become a robot for each Automate team in round 3 .

Each team will be given:

1. raw materials to be used for the simulation, consisting of Lego Toys blocks, and

2. an assembled prototype of the plane

Using the raw materials, prototype, Figure 1 and Table 1 , you will have 5 minutes to devise a manufacturing process. Raw materials can be placed by each assembler. The process you devise must conform to the team type restrictions described below. Any practice assembly done during this time must be broken down to individual blocks (raw materials) before the simulation starts.

Your team will manufacture planes for four or more rounds of five minutes each. The instructor will announce the beginning and end of each round. At the end of each round, your team's Accountant will count finished goods and work-in-process inventory and calculate net profit for your team. These figures will be audited by a consultant, another team's accountant, or the instructor. The Accountant records the figures in the Team Performance Summary table (Table 2) and reports them to the instructor, who displays the WIP value and Net Profit for each team on the board for all to see so that teams can see where they stand in the competition.

After the last round, the results will be discussed to help you make sense of the exercise and link the experience to theory and business practice. Guidance for the debriefing is provided to instructors in the Teaching Note (not available to students).

\section{II.2. Automate Team(S)}

The Automate team(s) must follow a linear, sequential process similar to a traditional assembly line, with limited communication among workers. The classroom may already have desks set up in a row for you to use. If you don't see this, ask the instructor where your assembly line should be located. The team appoints a supervisor. All other players are assemblers. Each assembler performs a different step in the process and may not help other assemblers. Assemblers may communicate with the supervisor, but not each other both during and between the manufacturing rounds. The supervisor cannot perform assembly, however the supervisor (and only the supervisor) can move work-in-process (WIP) from assembler to assembler. Once the simulation begins, the manufacturing process may not be changed.

Between the second and third rounds, the Automate team receives an additional resource in the form of an additional team member (hereafter referred to as "the robot"). The robot must be added to the workstation that has

\footnotetext{
${ }^{3}$ The differences in resources, information sharing and flexibility for the two types of teams are proxies for two different ways to use IT: to automate or informate. This will be explained further in the debriefing discussion.

${ }^{4}$ The exact numbers are decided by the instructor.
} 
the worst bottleneck in the assembly line. This is where inventory has backed up the most during Round 2. The robot supplements the member currently assigned to that task, performing the task in the same way.

\section{II.3. Informate Teams}

Informate teams work as flexible 'cells'. You may manufacture planes any way you wish, and change the way you do so at any time. You have no communication or assembly restrictions upon you. You may communicate freely with each other to sharing ideas. You can also reallocate work between members as you wish, e.g., you may help other team members who are falling behind. Informate teams have the same number of members in all rounds.

\section{II.4. Accountants}

One member of each team acts as an accountant to count the number of units finished and work in process and calculate net profit at the end of each round according to the rules below.

\section{II.5. Consultants}

In addition to the Automate and Informate team members, the simulation needs consultants and you may volunteer to act as one. ${ }^{5}$ The consultants roam the "factory floor" and take note of the business processes adopted by each team. They also note how the addition of the robot's affects performance in the automation team(s) and how different approaches to communication across the process steps affect performance in the Communication teams. In short, their goal is to identify characteristics that significantly affect performance. They share their findings with the entire class in the debriefing. One or more Consultants will switch roles to become a robot for an Automate team in round 3 .

\section{II.6. Profit Calculation Rules}

Profit is calculated by the Accountants at the end of each five minute round using the Team Performance Summary template in Table 2. Profit is calculated based on shipments of completed goods less a charge for carrying costs of inventory. At the end of each round the number of finished units (all are assumed to be shipped) and the number of units in process (WIP) are counted to calculate the Gross Profit, Carrying Costs and Net Profit of each team. The cost of each finished unit is $\$ 600$. Each finished unit is considered sold at the end of the round at a price of $\$ 700$, thus earning a gross profit of $\$ 100$.

Work-in-process (WIP) units are valued according to the percentage of completion of each unit. For example, a unit that is fifty percent complete is valued at $.50 \times \$ 600=\$ 300$. Cost of WIP can be done using a heuristic of $25 \%$ for units less than half complete, and $75 \%$ for those more than half complete but not finished, although other heuristics (e.g. 50\% for all units in WIP) are possible. This will be announced by the instructor. The team incurs a cost of carrying WIP in each round equal to $10 \%$ of the value of WIP inventory. Since the focus of this simulation is on the manufacturing process and not on the supply of raw material, no carrying costs are assigned to raw materials.

We thank Patrick Wheeler and anonymous reviewers from the AAA IS section for their constructive suggestions concerning earlier versions of this paper. Support for this paper was provided by a Seafirst-Volpe grant from the Albers School of Business and Economics at Seattle University.

\footnotetext{
${ }^{5}$ Depending on class size, three to five student volunteers are selected as consultants. The exact number is such that it keeps the sizes of all production teams equal. This will be decided by the instructor.
} 
Table 2

Team Performance Summary (One For Each Team)

\begin{tabular}{|l|c|c|c|c|}
\cline { 2 - 5 } \multicolumn{1}{c|}{} & \multicolumn{3}{c|}{ Team Name: (Automation / Informate \#1 / 2 etc.) } \\
\hline & $\begin{array}{c}\text { Gross Profit } \\
=\$ 100 \times \text { } \# \text { of } \\
\text { finished units }\end{array}$ & $\begin{array}{c}\text { WIP } \\
=\% \text { complete units } \\
\mathbf{x} \$ 600\end{array}$ & $\begin{array}{c}\text { Carrying Costs } \\
=10 \% \text { of WIP }\end{array}$ & $\begin{array}{c}\text { Net Profit } \\
\text { Gross Profit less } \\
\text { Carrying Costs }\end{array}$ \\
\hline Round 1 & & & & \\
\hline Round 2 & & & & \\
\hline Round 3 & & & & \\
\hline Round 4 & & & & \\
\hline
\end{tabular}

\section{APPENDIX A REPRESENTATIVE STUDENT COMMENTS ABOUT THE SIMULATION}

\section{A. Question: What were the significant things you learned in the exercise?}

\section{Responses:}

- $\quad$ There are two types of IT that managers should consider when making capital budgeting and investment decisions: automation and communication. Each one serves its purpose and an organization's requirements for each type will differ at different times.

- I thought that the exercise was a wonderful example of how important quick and open information lines can be solving problems in processes. I also discovered that automation is not always the best way for a company to improve their production.

- $\quad$ Automation is not always the best upgrade in information systems. I was always under the impression that automation always improves a business operation, not hinders it. I can't say that I learned that communication is essential in information systems because I already knew that.

- $\quad$ Automation cannot significantly improve a system if it is already balanced. Most systems have a floating bottleneck and needs to be tracked. It can do a significant amount in helping out the efficiency of a system.

- $\quad$ Even though adding another person to the assembly line sounds like it would make things more efficient, it is not always the best thing.

- $\quad$ Automation is not always going to solve floating bottlenecks. Communication IT helps to improve process, locate where problems are, etc.

- $\quad$ The significant thing I learned in the exercise was that communication is very important [in comparison to] automation. A lot can be done with proper communication.

- $\quad$ Communication is very important. The difference between open and closed management styles. What kind of technologies to use given companies' operations.

- $\quad$ Automation isn't always the answer; the system has to be prepared to have automation, meaning they need communication.

- I liked the way the exercise pointed out the limitations lack of communication puts on a system and how, when you do communication you can find inefficiencies in the system and work to correct them.

- $\quad$ One of the things I learned was that when you stop one bottleneck in a process, it usually creates another one someplace else. This is why it is called a floating bottleneck. I also learned that sometimes improved communication is sometimes better than improving or adding another machine (automation).

- Communication is important within a company, such as emailing each other or letting someone know if something is going bad. It is important to have IT better than automation because IT is a better communicator and will eventually increases business as in automation it was hard to communicate who each other and even though we receive a robot and did better we would eventually level out. 
- Communication, streamlining, open to changes, everyone has or needs a voice, information flow, especially in a dynamic work environment.

- I learned that information and communication systems are important because they enable the organization's people to capture and exchange the information needed to conduct.

B. Question: What did you like most about the exercise?

Responses:

- $\quad$ Learning via an actual example tends to make insights hit home much more because you have seen them in action versus just hearing ideas presented in lecture.

- A significant example of the effect of floating bottlenecks in operations management is observed in the simulation exercise, which is pretty interesting. The remarkable increase in the work in process and in the finished goods of the automation group after introducing the robot highlights the effect of bottlenecks in a production process. Moreover, the whole idea of trying to visualize the complexities involved in production, operations management etc. with the simulation exercise is unique and interesting.

- What I liked the most was when my group had to change the strategies in the production to make the company become more profitable. We communicated each other to find out what process didn't work and which area in the production should be improved.

- Building the planes and computing with other class groups. We consistently improved because we communicated ideas on how to improve our system. We also worked well in a team. I was a little surprised how different groups came up with different ideas on how they would assemble their planes.

- It was fun. I am a very competitive person and to get the opportunity to compete with my classmates is a fun thing for me.

- $\quad$ From the simulation I could recognize how in the real world a communication system is very important. 


\section{REFERENCES}

1. Albrecht, W. S. and R.J. Sack . 2000. Accounting Education: Charting the Course through a Perilous Future. Sarasota (FL): American Accounting Association.

2. Algeo, David. 1999. Strategic Management of Information Systems, www.cs.tcd.ie/courses/ism/smis/topics/req_fut/req_fut.htm, Jan 6)

3. $\quad$ Becker, R. 1998. Taking the misery out of experiential training. Training 35 (February): 78-88.

4. Bhattacharya, S. 2005. In Jane Gerold's The ERP Express. Automation World, January, p. 45

5. Bingi, P., M. Sharma and J. Godla. 1999. Critical issues affecting ERP implementation. Information Systems Management. Summer. Vol. 16. Iss. 3. pp.7-14.

6. Brookfield, S. D. 1990. The Skillful Teacher on Techniques, Trust, and Responsiveness in the Classroom. San Francisco, CA: Jossey Bass Publishers.

7. Brynjolfsson, E. 1994. Technology's true payoff. Informationweek. Oct 10, (496):34-36.

8. Brynjolfsson, E. and Hitt, L. M. 1995. Information Technology as a Factor of Production: The Role of Differences Among Firms. Economics of Innovation and New Technology. 3, 4, 183-200.

9. Brynjolfsson, E. and Hitt, L. M. 1996. Paradox Lost? Firm-level Evidence on the Returns to Information Systems Spending. Management Science. Apr, 42(4):541-558.

10. Bureau of Economic Analysis. 2006. Table 5.3.5 - Private Fixed Investments by Type. [WWW document], March 30. Retrieved April, 2006 from http://www.bea.gov/bea/dn/nipaweb/SelectTable.asp

11. Compass. 1999. The COMPASS International IT Strategy Census 1999 Benelux: COMPASS Publishing BV. Available at http://www.compassamerica.com/home census.htm

12. Dehning, B. and V.J. Richardson. 2002. Returns on Investments in Information Technology: A Research Synthesis. Journal of Information Systems 16 (1) Spring: 7-30.

13. Dehning, B., V.J. Richardson and R.W. Zmud. 2003. The value relevance of announcements of transformational information technology investments. MIS Quarterly 27 (4): 637-656.

14. Duimering, P.R., Safayeni, F., and Purdy, L. (1993) Integrated Manufacturing: Redesign the Organization before Implementing Flexible Technology Sloan Management Review, Summer, 47-56.

15. Financial Times (London). 1998. SAP in \$500m US lawsuit. Information Technology Section, September 2, p.2.

16. Flynn, B.B. and Flynn, E.J. 1999. Information-Processing Alternatives for Coping with Manufacturing Environment Complexity. Decision Sciences. 30, 4, pp. 1021-1052.

17. Forrester Research Inc. 2002. Managing in the Recovery: Using Technology to Recapture Momentum. $15^{\text {th }}$ Annual Executive Strategy Forum.

18. Gurbaxani, V., and Whang, S. 1991. The Impact of Information Systems on Organizations and Markets. Communications of the ACM. January, 59-73.

19. Jenson, R.L. and I.R. Johnson. 1999. The enterprise resource planning system as a strategic solution. Information Strategy: The Executive's Journal. Vol. 15. No.4. pp.28-33.

20. Kaplan, R.S. and A.P. Hutton. 1997. Romeo Engine Plant. Harvard Business School. Case 9-197-100, April 23.

21. Kraemer, K.L, Dedrick, J. and L.Yoshimura. 1998. IT Use at Dell. CRITO working paper. University of California, Irvine.

22. Meyers, C and T.B. Jones. 1993. Promoting Active Learning. San Francisco, CA: Jossey-Bass Publishers.

23. Oh W., J.W. Kim and V. Richardson. 2006. The Moderating Effect of Context on the Market Reaction to IT Investments. Journal of Information Systems. 20:1 (Spring), pp. 19-44.

24. Ranganathan C. and C.V. Brown. 2006. ERP Investments and the Market Value of Firms: Toward an Understanding of Influential ERP Project Variables. Information Systems Research, Vo.17, No. 2, pp. 145161.

25. Ross, J.R. and P. Weill. 2002. Six IT Decisions Your IT people Shouldn’t Make. Harvard Business Review. November, 84-91.

26. Schein, E. H. 1992. The role of the CEO in the management of change: The case of information technology. In T.A. Kochan and M. Useem (Eds.), Transforming Organizations. Oxford: Oxford University Press. 
27. Seikman, Philip. 2002. Jeep Builds a New Kind of Plant. Fortune. Industrial Management \& Technology Section, November 11

28. Steensboe, C. 2002. Information Integration in the Global Enterprise. Houston, TX, Kalido Inc.

29. Stiroh, Kevin J. 2001. Information Technology and the U.S. Productivity Revival: What Do the Industry Data Say? Federal Reserve Bank, Mimeo. January 24, 44 pp.

30. Tallmadge, G. Kasten and J. W Shearer. 1969. Relationships among learning styles, instructional methods, and the nature of learning experiences. Journal of Education Psychology 60, (June): 222-230.

31. Venkatraman, N. 1994. IT-Enable Business Transformation: From Automation to Business Scope Redefinition. Sloan Management Review. Winter. pp. 73-87.

32. Wessel, David. 2002. It's How Business Utilizes Computers that Counts. Wall Street Journal. November 14.

33. Zuboff, S. 1988. In the Age of the Smart Machine: The Future of Work and Power. New York: Basic Books. 


\section{TEACHING NOTE}

\subsection{Preparation And Setup Of The Simulation}

\section{Handouts}

Section II can be distributed to students several days before the simulation for them to read. This reduces setup time required in class. If this is done, teams should be selected randomly the day the simulation is run to mitigate the effect of groups forming and practicing assembly beforehand.

During the debriefing discussion a one page handout of Figure 2 and Table 4 (see the last page of this note) is given to each participant.

\section{Blocks (Raw Materials)}

The day before the simulation the blocks needed by each team for all four rounds (i.e. for 130 planes per group) should be put into a separate plastic tub or bag for distribution at the beginning of the simulation.

\section{Number and Type of Teams}

The appropriate number of teams (Automate and Informate together) depends on the class size. There should be at least three teams with a minimum of five and maximum of eight members per team. It is preferable to have more teams with fewer members rather than fewer teams with more members. We suggest having one Automate team and three Informate teams in a class of 25-35 students.

Experience indicates that the performance of Informate teams can vary widely. Having more than two Informate groups makes it more likely that most information-sharing enabled behaviors and their significant performance impacts will be observed and discussed. Much less variation in behavior is observed in, and less pedagogical benefit gained from, multiple Automate groups. For classes of 40 or more, Informate teams would be added but no more than one Automate team would be added (for a total of two Automate teams). A larger number of groups does not affect time spent in setup or the manufacturing rounds, but would require more time for input during the debriefing discussion.

\section{Classroom desk layout}

On the day of the simulation, if the classroom has movable desks, several should be joined together to form a row long enough to accommodate a linear assembly line for the Automate team. If this is not possible, the team should use space on the floor for assembly.

\section{Number of Rounds}

The number of rounds is determined by the instructor depending on the time available. Each additional round requires 10 minutes ( 5 minutes for break time plus 5 minutes for manufacturing). The instructor should avoid announcing the total number of rounds the simulation will have so that students do not stop production near the end of the last round to manipulate profits. The instructor may find a kitchen timer helpful to signal the end of each round.

\subsection{Leading The Discussion: Overview Of Key Points}

The five key points to be brought out in the discussion are described below. 
1. Using IT to automate has very different impacts on business processes than using it to informate. Zuboff's (1988) seminal work is the reference here. It provides a detailed theoretical description along with several case studies.

(A) Automation (in its traditional pre-computer role) replaces and multiplies human physical labor. In its more contemporary form, automation may capture information but does not necessarily share it across several steps in a process. This means analysis and learning are limited to change within individual process steps. Automation may be flexible but is almost always less flexible than the human labor it replaces. Automation is appropriate when a business is looking for an increase in productivity for a physical task such as scanning a customer check posting transactions to a customer account, or for improved consistency in the performance of that task, such as using robots to paint automobiles.

(B) Using IT to informate enables information storage, organization and sharing across steps in a business process, facilitating learning. This learning enables short term process adjustments and long term process reengineering.

ERP systems include both uses of IT (Ranganathan and Brown, 2006). To preclude the automation team from enjoying the benefits of cross-process communication, assemblers at each station are not allowed to change the output of their individual task. They are permitted to change how they perform it to allow for individual task-level learning over time. If automate team assemblers were able to flexibly reconfigure their outputs this would reflect cross-process learning, a product of the communication and analysis associated with using IT to informate. This provides a baseline to assess the relative value of investments in IT that automate vs. those that informate.

2. These distinctions have significant implications for process performance:

(A) Using IT to automate can increase performance in three ways: (i) by performing the task more quickly, increasing throughput (ii) by increasing capacity due to the ability to be productive 24 hours a day, 7 days per week, and (iii) by increasing consistency in the performance of a task, thereby increasing conformance quality. These are usually associated with a one-time step improvement in performance. The improvement is often less than the potential of the automated component alone because of capacity constraints in other steps in the production process, leading to the phenomenon of 'floating bottlenecks' (Goldratt and Cox, 1992). Automation inherently lacks the learning and responsiveness provided by IT-enables communication across processes, and as noted above, is less flexible than the human labor it replaces (Duimering et al, 1993).

(B)

Using IT to 'informate' stores, organizes, analyzes and shares data across steps in the business process, enabling learning and iterative modification (Zuboff, 1988) or even transformation of the process (Venkatraman, 1994). This can lead to continual performance improvement. In the simulation often, though not always, communication effects start off slowly and then increase to outstrip those of automation. The simulation is structured so that the Informate teams can not only communicate and analyze but also reallocate work tasks dynamically. Theoretically, the benefits of flexibility are distinct from those of communication. However, the two are intertwined in workplace settings: learning via communication and analysis can only improve performance if business processes can be changed because of that learning.

3. Given 1 and 2, managers with limited investment budgets should consider carefully which mix of these two uses of IT is best for their firm. Using IT to informate is most likely to be more productive in settings that require significant learning on an ongoing basis, for example, in dynamic complex environments. The ability to communicate and analyze with IT is especially important if there are no other means of information sharing, as in the case of geographic dispersion, or if the volume of data is too great for traditional paper and manual methods. This provides a partial explanation of why Enterprise Resource Planning systems have become so popular. The learning aspect highlights that managers need to manage the human element of a communication IT implementation so that it is used as an occasion for learning and change. Automation will be more productive in settings where processes have low levels of interdependence or are very stable, and the automation is able to resolve existing production bottlenecks (Zuboff, 1988). 
4. These two uses of IT and their performance impacts are distinct, but not mutually exclusive. As just noted, IT used to automate typically addresses individual task conformance quality and output capacity issues. IT that informates typically facilitates data analysis and adaptation across several automated tasks. The two uses are often complementary in their effects on performance. This is often true in full scope ERP implementations. In a fully automated "lights out" factory the steps in the business process are tightly linked, making immediate sharing of high volumes of data vital to maintaining the factory's smooth functioning. Here informating IT is a complement to rather than a replacement for automation. The central issue for managers is ensuring that they invest in the right amount of both uses of IT. Automation investments made without adequate complementary investments in informating IT needs may not be able to achieve their full promise. In the 1980s American firms tended to put in expensive standalone islands of automation that were not well linked to adjacent steps in the business process, often leading to underutilization of automation's capabilities. In contrast, Japanese firms implemented less sophisticated automation designed to be adjusted quickly in response to the needs communicated from other steps in the business process. This was much more productive (Duimering et al, 1993). Students should not conclude that using IT to informate is inherently more effective than using it to automate; rather each has very different effects which need to be explicitly considered in understanding how IT investments create value.

5. It is important for students to be aware that merely investing in IT of either type will not necessarily improve communication or performance to the extent seen in the simulation. The highest-performing teams in the simulation demonstrate the level of benefits that could arise from each use of IT. As described in the introduction, IT projects often fail and are a source of disappointment to the executive suite. Several recurring causes of failure have been identified in research and business practice. IT can be implemented but not used as intended because the system's design conflicts with social norms in the organization. Further, Ackoff (1967) points out that managers often don't need IT to provide more information but rather to filter or analyze it, and that increased communication can reduce performance if subunits have conflicting performance goals. This indicates there are several factors moderating the relationship between IT investments, coordination, and performance. Though the simulation does not directly address these issues, it could be used as a point of departure for further discussion.

\subsection{Conducting The Debriefing Discussion}

We begin the discussion by asking, "Why did we do this exercise?" Frequent answers on the lighter side include "for fun" and "to get our competitive spirit flowing." Other answers may be, "to understand different manufacturing processes" or "to understand how learning affects performance." We start by pointing out that the critical learning objective of this exercise is neither to improve students' manual dexterity nor find the 'one best way' to assemble a Lego airplane, but to demonstrate how automation and informate ITs affect performance differently.

We display the performance results of all the teams by writing on the board the WIP and net profit values for each group at the end of each round. In most cases the performance for each team is better in later than in earlier rounds. Students usually attribute this to the learning that occurs over the periods. We relate how learning is critical in the current business environment, marked by global competition and shorter product life cycles.

Next, the results are discussed. The path of the discussion varies with the relative results of teams. The most likely and other possible scenarios are discussed below. These discussions tend towards concluding that in most business settings Communication IT will have a greater impact on performance than Automation IT, but as noted in section 3.1 \#3 above, this is highly dependent on the context. Thus the instructor could choose to devote time to discussing scenarios in which Automation IT would have a greater impact on performance than Communication IT. The scenarios below address the scenarios that have been encountered most often.

\section{Most likely scenario - Informate team(s) outperform Automate team}

The expected outcome of this simulation is that the Informate teams (see Table 3, Teams 'Front Row', 'Third Row' and 'Fourth Row') will outperform the Automate team (Table 3 Team 'Second Row'). The Informate 
teams typically realize continuous performance improvements through the rounds. The Automate team may achieve a marked improvement when the robot is added, but it will likely be a fixed step improvement.

One of the Informate teams is selected and asked why their performance improved. We then compare the team's performance with other teams and ask, "Your performance was better than other teams. What do you think was special about your team?" A typical response from a better performing team member would be that it was because they were smart, or had discovered the best way to make the product.

We turn their attention to differences in their production processes by selecting the team that had the most significant improvement in performance and probing how they built the product, how this changed over time, and how communication and analysis facilitated this change. Two typical changes are:

1. One team redeployed a person before the second round. That resulted in a jump in the second round, with a steady improvement later. The change was made to take care of a bottleneck that the team encountered, and that the team had discussed various courses of action.

2. Another team's performance improved because a team member came up with an idea of how to better put wheels on a toy airplane. The member came up with the idea while waiting for the bottleneck in that step.

The other informate teams that had significant improvements describe whether their experience was similar. We also ask the consultants what differences they observed, requesting that they focus on how much each team's process changed over the simulation (but not the details of exactly how it changed) and what brought about the change. We ask questions about communication and analysis among the members. Typical comments would be:

"In the first round, no one was talking. All were doing their own thing. In the second round they started talking and helping each other."

"Frequent communication within a group was indispensable to improve the results. The moving forward of WIP in manufacturing process heavily relied upon the other team members yelling to her."

Next, the automate team members are asked to describe their experience. This provides a contrast to the informate groups. The Automate team tends to have less improvement subsequent to the third round (see Table 3), and sometimes from the first to the second rounds because they are not allowed to communicate during or between rounds. Though the automate team cannot communicate directly and cannot change the structure of their process, it is still likely that individual workers learn how to better do their tasks. We ask if the members noticed individual improvements. Such learning can mitigate or exacerbate bottlenecks in the production process. Many Automate team members express frustration that they were 'artificially' prevented from solving problems by the simulation rules. One response is to ask the students if they can imagine a real world scenario where they are different production departments out of visual contact with each other.

At this point it is useful to ask the entire class how much they knew about Lego product assembly at the beginning of the exercise (presumably little). The performance summary by team by round indicates that significant learning that has occurred in the teams. The discussion highlights that successful teams were able to identify and address problems and opportunities by communicating and dynamically reconfiguring their work allocations. Being able to communicate, analyze and reconfigure processes are the three pillars of learning that drive the significant increases in performance. It should be stressed that communication, analysis and the ability to change processes are all needed for performance improvement. Firms that learn from informating IT but cannot reconfigure their processes (perhaps due to personnel or equipment limitations) will not be able to substantially improve their performance.

Managers making capital budgeting decisions about their (perhaps) largest capital expenditure category must plan to optimize performance over the long run rather than just two or three periods. This is especially relevant to ERP acquisition decisions. Given that the effects of learning grow over several periods, and may outstrip the benefits of traditional automation in even a very short time frame (only 4 rounds), managers must think carefully about the differential effects of these different uses of ITs. This does NOT imply that using IT to informate is 
inherently more effective than to automate; rather each use has different effects which need to be explicitly considered in understanding how IT investments create value.

\section{Other possible scenarios}

1. The Automate team starts ahead but the Informate teams surpass it. A teaching point here is that the assembly line group has one very specialized way of communicating and analyzing information. It is not the worst way to communicate or analyze. Assembly lines spurred mass production and have been successful for decades. One might expect it to outperform the Informate teams in the initial rounds until the Informate teams develop a more efficient task allocation. This reflects the effect of communication, analysis and learning on performance over time.

Another potential explanation for why the Informate teams outperform the Automate team is the existence of bottlenecks. Typically bottlenecks arise in assembly lines resulting in lower throughput and high inventory levels. They are less likely to occur in flexible lines because communication and analysis facilitate the identification and resolution of problems and workers can be dynamically redeployed. Interestingly, the addition of the "robot" to the Automate team rarely resolves all bottlenecks: typically the bottleneck merely migrates to a different process. This illustrates nicely the limitations of any solution that does not take into consideration the entire business process, and the important of being able to reconfigure/redeploy assets. Typically automation is not re-deployable. This can be a substantial weakness in dynamic settings.

2. The Automate team starts ahead and Communication improves but does not surpass the Automate team. In this scenario there is most likely a communication or analysis problem in the Communication group arising from:

A. The individuals in the group are coming with good ideas but not sharing them. This precludes learning, change and the performance improvement that change would bring about.

B. The team's initial production configuration was ineffective but they were unable to change their assembly process quickly enough to recover.

3. An Informate team starts better but loses ground in the third round so that the Automate team wins. The instructor could probe the Informate team and attempt to detect why their performance did not improve. Often the group has had serious communication or analysis problems. Another contributing factor may be that the assembly line hit upon a well-balanced production line, either before the robot was added, or afterwards. In the first case, addition of a 'robot' increases performance only slightly.

\section{Summing up and general frameworks}

Regardless of the results scenario, we then synthesize students' observations by presenting Figure 2 . We begin by handing out Figure 2 and Table 4. In reviewing Figure 2, we observe that communication and analysis are the backbone of coordination and learning both in the simulation and in practice. An important difference in practice is that the both communication and analysis are much more complex. The level of complexity may range from the requirements of 50 employees in the same building to 50,000 employees all over the globe. In these situations informate type activities are far more critical than for a business process involving only 5-8 people, and the potential benefit of informating IT increases accordingly. IT plays a critical role in such communication and analysis. For example: e-mail, document exchange, supply chain management (such as at Jeep) and production coordination via custom or ERP systems (such as in Romeo Engine Plant) all can have a significant impact on overall production efficiency, quality and timeliness.

Automation of individual steps of the business process can also have a significant impact on throughput, capacity and conformance quality. The simulation focuses on throughput effects. All of these effects are however usually associated with a one-time jump in performance because of bottlenecks in up-or downstream processes. If a sufficient number of steps can be automated and linked with communication IT so that data can be analyzed in real time, then the process can be redesigned and a sufficient number of bottlenecks removed for a transformational change in performance (Venkatraman, 1994). 
We point out that the potential for learning and thus performance improvement for Informate teams was less than what might be encountered in practice because the product assembled was relatively simple and there were only a few minutes of manufacturing activity. In practice, the amount of data to be stored, organized, shared and analyzed would be much greater. These demands would be multiplied in settings where products are complex and life cycles last months. In such settings IT that facilitates informating has a much greater opportunity to make an impact. A significant proportion of the benefits of ERP systems arise from their use as informating technologies. This is supported most recently by Ranganathan and Brown's (2006) large scale empirical study of ERP implementations, which found that the stock market reacts much more positively to announcements of ERP systems that integrate across multiple functions and locations.

The debriefing concludes with the presentation of Table 4, a framework that students can apply when evaluating IT investment projects. While most large IT projects, and particularly ERP systems, include both uses of IT, it is helpful for managers to try to discern the mix of the two uses in a project in order to critically evaluate its expected benefits. More specifically, are the claimed benefits plausible given the IT use mix being implemented and the business setting of the firm? If the benefits are plausible, has the organization developed plans for making necessary changes to its structure, business processes and incentive system for the system implementation to be successful e.g., if information sharing and analysis are vital, will the users who must share and analyze information be organized as a group and compensated for these activities?

There is no formula for a 'proper' mix of automation and informating IT: this will vary with business process requirements and the capabilities of both uses of IT. An appreciation of the very different benefits associated with using IT to automate or informate provides an effective perspective for managers to critically evaluate IT investments.

As a final task the students are asked to answer the following three questions on a preprinted form:

1. What were the significant things you learned in the exercise?

2. What did you like most about it?

3. What could have been done to make the experience better? ${ }^{6}$

\subsection{Supplementary Readings and Assignments}

For advanced classes the following two readings are useful readings before or after the simulation:

1. Gurbaxani and Whang (1991) describes the impacts of communication ITs and automation ITs on organizational structure using transaction cost and agency theory.

2. Steensboe (2002) describes the impact of these uses of IT on global firms in practice. simulation:

These questions can be given as homework afterwards to reinforce the students' experience in the

1. What indicators would you look for in determining whether your investment in technology was paying off? If one of those indicators were return on assets and it did not show improvement that could be attributed to the technology, what other reason might explain the apparent lack of performance?

2. $\quad$ Forester Research Inc states, "Companies need to link their investments in technology with changes in their business process." Explain the implications of this statement. Relate it to what you know about ERP implementations. (Wall Street Journal, 2002)

\footnotetext{
${ }^{6}$ Responses to this question are already incorporated in the simulation and, therefore, are not listed in the paper.
} 


\section{REFERENCES}

1. Ackoff, Russell L. 1967. Management Misinformation Systems. Management Science. December, 14(4):B147-156.

2. Duimering, P.R., Safayeni, F., and Purdy, L. 1993. Integrated Manufacturing: Redesign the Organization before Implementing Flexible Technology. Sloan Management Review, Summer, 47-56.

3. Goldratt, E.M. and J. Cox. 1992. The Goal: a process of ongoing improvement. New York: North River Press.

4. Gurbaxani, V., and Whang, S. 1991. The Impact of Information Systems on Organizations and Markets. Communications of the ACM. January, 59-73.

5. Ranganathan C. and C.V. Brown. 2006. ERP Investments and the Market Value of Firms: Toward an Understanding of Influential ERP Project Variables. Information Systems Research, Vo.17, No. 2, pp. 145161.

6. Steensboe, C. 2002. Information Integration in the Global Enterprise. Houston, TX, Kalido Inc.

7. Venkatraman, N. 1994. IT-Enable Business Transformation: From Automation to Business Scope Redefinition. Sloan Management Review. Winter. pp. 73-87.

8. Wall Street Journal. 2002. Study Questions Import of Technology Spending. 11/14/2002. http://online.wsj.com/aricle_email/0,,SB1037227683377630188,00.html.

9. Zuboff, S. 1988. In the Age of the Smart Machine: The Future of Work and Power. New York: Basic Books.

\section{Figure 2}

\section{Effect Of Information Technology On Performance}

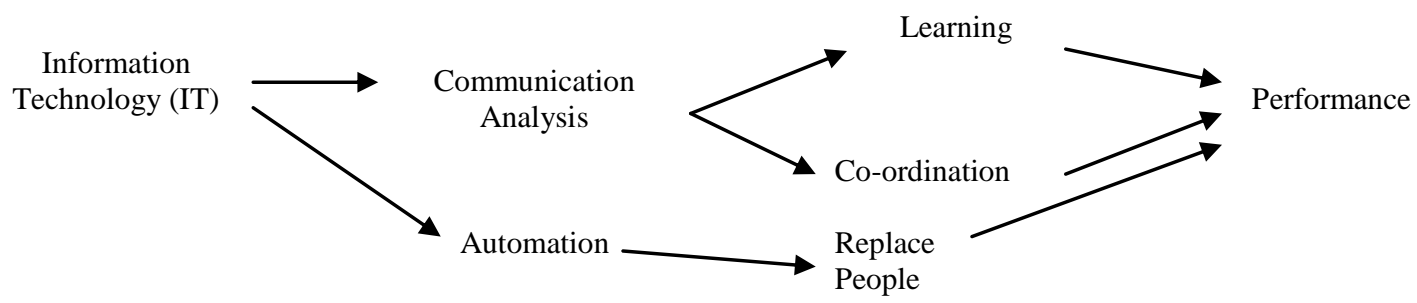


Table 3 Representative Team Performance Summary*

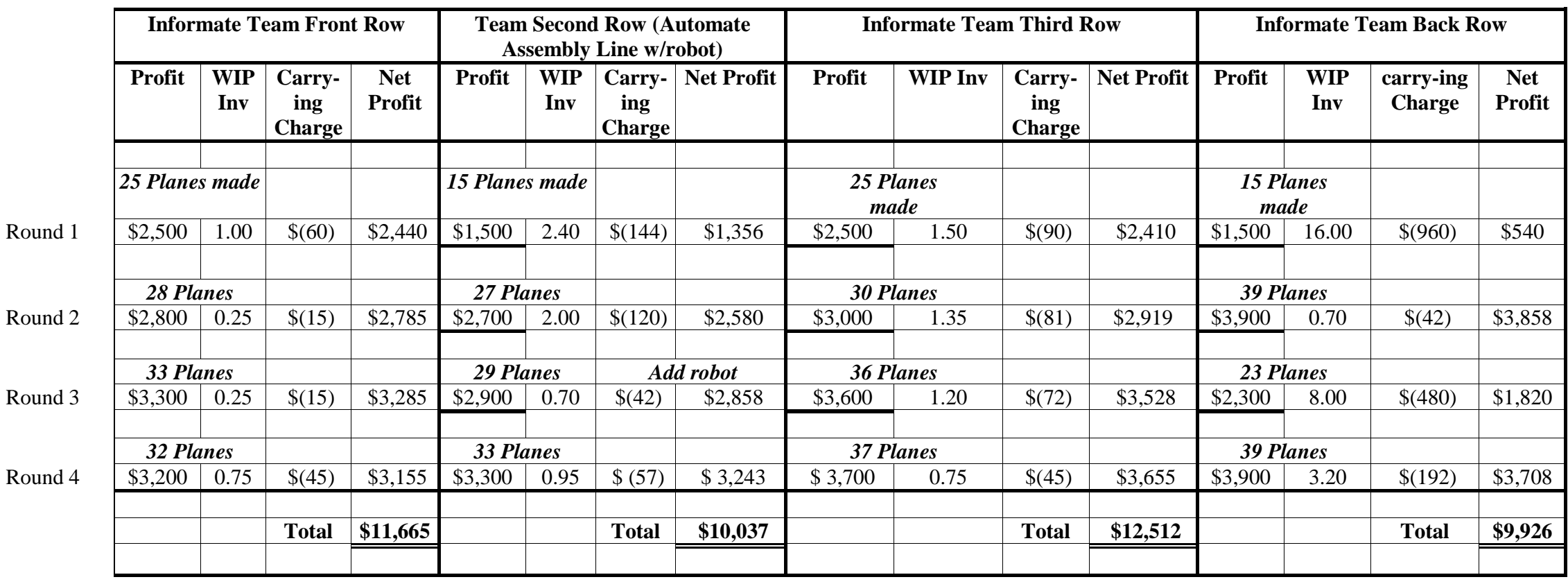

* The quantities produced reported above were achieved in simulations that built cars. We recommend building airplanes because car wheels are not readily available from Lego. Scoring:

Revenue per plane $=\$ 700$

Cost per plane $=\$ 600$

Profit $=\$ 100$ per plane

Carrying charge $=$ WIP Inventory times Cost (600) times 10\% 
Table 4 It Use Investment Evaluation Matrix (Based on Venkatraman, 1994)

\begin{tabular}{|c|l|l|}
\hline & \multicolumn{1}{|c|}{ Use IT to Automate } & \multicolumn{1}{c|}{ Use IT to Informate } \\
\hline Process Scope & Individual business process step(s) & $\begin{array}{l}\text { Storing, Organizing, Sharing, Analyzing information across } \\
\text { multiple business process steps }\end{array}$ \\
\hline $\begin{array}{c}\text { Benefits } \\
\text { Creating } \\
\text { Advantage }\end{array}$ & $\begin{array}{l}\text { Increased speed, capacity, reliability } \\
\text { in performance of a physical task }\end{array}$ & $\begin{array}{l}\text { 1. Increased speed, quality of coordination across several steps in } \\
\text { a given, static business process. } \\
\text { And possibly } \\
\text { 2. Increased communication enables learning, leading to } \\
\text { redesign/ transformation of the business process }\end{array}$ \\
$\begin{array}{c}\text { Potential } \\
\text { Duration of } \\
\text { Advantage } \\
\text { created }\end{array}$ & $\begin{array}{l}\text { Short term since usually standard, } \\
\text { off-the-shelf functionality }\end{array}$ & $\begin{array}{l}\text { 1. Medium term if a static process (1 above) since skill in } \\
\text { analyzing data, applying insights gained resides in groups of } \\
\text { managers and workers. Requires both IT system } \\
\text { interconnectivity and business practices supporting coordination. }\end{array}$ \\
$\begin{array}{c}\text { Ability to Cope } \\
\text { with Change in } \\
\text { Business Process }\end{array}$ & $\begin{array}{l}\text { Depends upon specific process and } \\
\text { automation. } \\
\text { Changes in how task is conducted } \\
\text { are usually highly constrained. } \\
\text { If physical task stable over time but } \\
\text { volume changes, automation likely } \\
\text { scalable. }\end{array}$ & $\begin{array}{l}\text { 2. Long term if redesign/transformation of the business process } \\
\text { since more difficult to replicate. }\end{array}$ \\
response to events affecting several steps in the business process. \\
\hline
\end{tabular}




\section{Student Handout}

Effect Of Information Technology On Performance

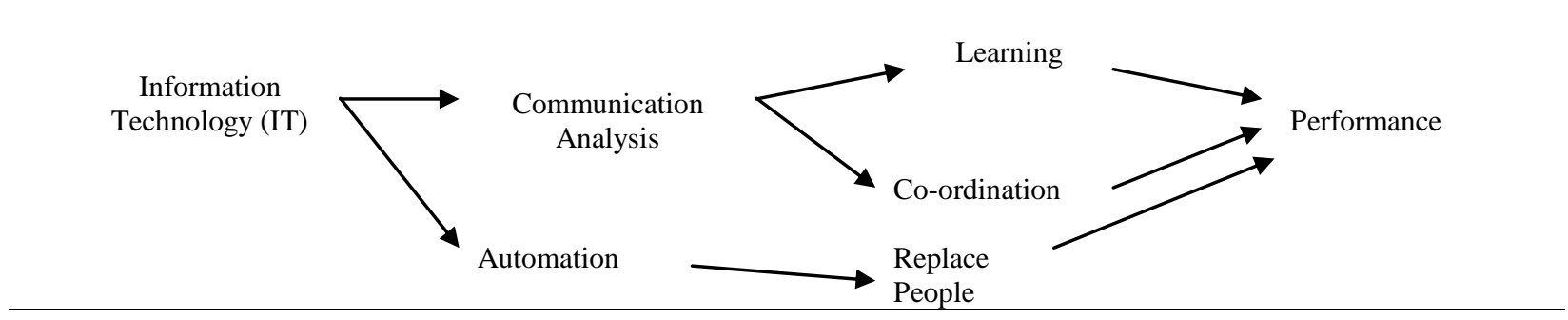

Investment Evaluation Matrix

(Based on Venkatraman, 1994)

\begin{tabular}{|c|c|c|}
\hline & Use IT to Automate & Use IT to Informate \\
\hline Process Scope & Individual business process step(s) & $\begin{array}{l}\text { Storing, Organizing, Sharing, Analyzing information across } \\
\text { multiple business process steps }\end{array}$ \\
\hline $\begin{array}{c}\text { Benefits } \\
\text { Creating } \\
\text { Competitive } \\
\text { Advantage }\end{array}$ & $\begin{array}{l}\text { Increased speed, capacity, reliability } \\
\text { in performance of a physical task }\end{array}$ & $\begin{array}{l}\text { 1. Increased speed, quality of coordination across several steps in } \\
\text { a given, static business process. } \\
\text { And possibly } \\
\text { 2. Increased communication enables learning, leading to } \\
\text { redesign/ transformation of the business process }\end{array}$ \\
\hline $\begin{array}{c}\text { Potential } \\
\text { Duration of } \\
\text { Competitive } \\
\text { Advantage } \\
\text { created }\end{array}$ & $\begin{array}{l}\text { Short term since usually standard, } \\
\text { off-the-shelf functionality }\end{array}$ & $\begin{array}{l}\text { 1. Medium term if a static process ( } 1 \text { above) since skill in } \\
\text { analyzing data, applying insights gained resides in groups of } \\
\text { managers and workers. Requires both IT system } \\
\text { interconnectivity and business practices supporting coordination. } \\
\text { 2. Long term if redesign/transformation of the business process } \\
\text { since more difficult to replicate. }\end{array}$ \\
\hline $\begin{array}{l}\text { Ability to Cope } \\
\text { with Change in } \\
\text { Business Process }\end{array}$ & $\begin{array}{l}\text { Depends upon specific process and } \\
\text { automation. } \\
\text { Changes in how task is conducted } \\
\text { are usually highly constrained. } \\
\text { If physical task stable over time but } \\
\text { volume changes, automation likely } \\
\text { scalable. }\end{array}$ & $\begin{array}{l}\text { High. Effective for uncertain environments as it supports quick } \\
\text { response to events affecting several steps in the business process. }\end{array}$ \\
\hline
\end{tabular}

